\title{
Assessment of nurses' patient safety culture in 30 primary health-care centres in Tunisia
}

Mohamed Ayoub Tlili, ${ }^{1,2}$ Wiem Aouicha, ${ }^{1}$ Mohamed Ben Dhiab ${ }^{3}$ and Manel Mallouli ${ }^{4}$

${ }^{1}$ Laboratoire de Recherche LR12ESo3, Faculté de Médecine de Sousse, Université de Sousse, Sousse, Tunisia (Correspondence to: Mohamed Ayoub Tlili: medtlili@hotmail.fr). ${ }^{2}$ Ecole Supérieure des Sciences et Techniques de la Santé de Sousse, Université de Sousse, Sousse, Tunisia. ${ }^{3 V i c e-D e a n, ~ F a c u l t e ́ ~}$ de Médecine de Sousse, Université de Sousse, Sousse, Tunisia. ${ }^{4}$ Département de Médecine Familiale et Communautaire, Laboratoire de Recherche LR12ESo3, Faculté de Médecine de Sousse, Université de Sousse, Sousse, Tunisia

\begin{abstract}
Background: Ensuring patient safety and health-care quality remain priorities and challenges worldwide and the role of nurses is essential to meet these challenges. Developing patient safety culture is a key component to improve patient safety and health-care quality.

Aims: To assess nurses' patient safety culture in primary health-care centres in Tunisia and to determine its associated factors.

Methods: This was a multicentre, cross-sectional descriptive study conducted across 30 primary health-care centres in Tunisia, using the French validated version of the Hospital Survey on Patient Safety Culture questionnaire. All the nurses working in these centres were invited to participate in the study $(n=158)$.

Results: The response rate for participation in the study was $87.3 \%$. The dimension of "teamwork within units" had the highest score (70.6\%). Three safety dimensions had low scores: "frequency of event reporting" (27.6\%), "staffing" (34.76\%) and "nonpunitive response to errors" (36.5\%). Two factors were associated with patient safety culture: participation in risk management committees, and district of the primary care centre.

Conclusions: The level of nurses' patient safety culture needs to be improved in primary health-care centres in Tunisia. Strategies to nurture patient safety culture should focus upon building leadership capacity that supports open communication, blame-free environment, teamwork and continuous organizational learning.

Keywords: Patient safety culture, nurses, patient safety, public health, primary care

Citation: Tlili MA; Aouicha W; Ben Dhiab M; Mallouli M. Assessment of nurses' patient safety culture in 30 primary health-care centres in Tunisia. East Mediterr Health J. 2020;26(11):1347-1354. https://doi.org/10.26719/emhj.20.026

Received: 12/06/19; accepted: 19/11/19

Copyright $@$ World Health Organization (WHO) 2020. Open Access. Some rights reserved. This work is available under the CC BY-NC-SA 3.0 IGO license (https://creativecommons.org/licenses/by-nc-sa/3.o/igo).
\end{abstract}

\section{Introduction}

Adverse events (AEs) remain a global challenge, and millions of people are prone to death or injury due to preventable medical errors (1) and several studies have shown the severity of these AEs in terms of cost, frequency and serious consequences (2). As a result, enhancing patient safety has become a priority for healthcare systems and providers (2).

The situation is more difficult and serious in developing countries with a higher risk of patient harm due to the limitation of resources and lack of adequate infrastructure. In Tunisia, a study in the town of Sousse showed that the rate of AEs varied between $10 \%$ and $11.3 \%$ (3). The rates of AEs vary according to the sectors, the nature of the services and levels of care, depending on the specific countries (4). Health care in Tunisia is divided into public and private structures. The public structures are organized on 3 levels of care. The front-line (first-line) structures include primary healthcare centres serving the community with primary and essential care. The secondlevel structures (regional hospitals) refer to a second tier of the healthcare system, in which patients from primary health care are referred to specialists in higher-level hospitals for treatment and specialized diagnosis. The third level of care provides specialized consultative care, usually on referral from primary and secondary care, along with teaching and research functions.

Primary healthcare centres provide the first contact for patients and quality and patient safety in these facilities are vital $(1,5)$. However, since severe and complicated cases requiring special treatment are handled in hospitals, both healthcare providers and local communities tend to underestimate the importance of primary healthcare services (1). In fact, it has been identified that a significant proportion of safety incidents arising in hospitals originate at the earlier levels of care (5), and some errors in primary care can result in severe consequences $(1,6,7)$. A study in Spain deemed that $64.3 \%$ of AEs in primary care were preventable (8).

To prevent such harm, there is a growing recognition of the importance of establishing a patient safety culture (PSC) (2,9-12). PSC is defined as the product of individual and group values, attitudes, perceptions, competencies and patterns of behaviour that determine commitment to the style and proficiency of an organization's safety management (13). Furthermore, it should be noted that development of PSC starts with evaluation of its 
existing level (1,14). In particular, nurses as healthcare providers believe that patient safety is primarily a nursing responsibility $(14,15)$, and it has been estimated that $>90 \%$ of potential medication errors are discovered by nurses (14). Thus, nurses are considered key to safety improvement and play a vital role in enhancing quality of care $(12,14,16)$. The nature of work carried out by nurses and the roles they perform provide them with opportunities to reduce AEs and intercept healthcare errors before they occur (12). Thus, assessment of nurses' PSC is crucial to identify the strengths and weaknesses of their safety culture and to help units' caregivers identify the patient safety problems that they have.

It has been shown that the level of PSC in Tunisia is low $(10,17,18)$. This can be explained by the lack of professional involvement in training sessions on patient safety and the late introduction of the concept of PSC in Tunisia. For example, a study in Tunisian operating rooms showed that all dimensions of PSC needed improvement (10). Another study showed that no dimension was considered as developed (17). To our knowledge, no studies have assessed nurses' PSC in Tunisia, specifically in crucial frontline healthcare facilities that deliver essential care. Therefore, we assessed nurses' PSC in Tunisian primary healthcare centres and determined its associated factors.

\section{Methods}

\section{Study design, setting, duration and participants}

This was a cross-sectional multicentre study from January to April 2016 in all 30 primary healthcare centres in Sousse, Kasserine and Kairouan, Tunisia. These centres are partners of the Faculty of Medicine of University of Sousse and carry out consultations 4 days a week. Each centre has 1 or 2 doctors and an average of 4 nurses.

All 158 nurses involved in the selected primary healthcare centres were invited to participate in the study and 138 provided survey feedback. Nurses were divided into registered nurses and specialized nurses with specific additional training for particular specialties (emergency, paediatric and geriatric care). Nurses who were not involved in healthcare practices and those with $<1$ month's experience were excluded. This exclusion criterion was recommended by the questionnaire's user guide provided by the Coordination Committee of the Clinical Evaluation and Quality in Aquitaine (CCECQA), which was responsible for validation of the French version of the questionnaire (19).

\section{Questionnaire}

The current study used the French version of the Hospital Survey on Patients Safety Culture (HSOPSC) questionnaire, which was translated and validated by the CCCEQA (20). It is the most broadly used instrument to evaluate PSC because of its favourable psychometric properties; it is a valid and reliable instrument that allows the study concept (PSC) to be measured appropriately (21). The
Cronbach a was 0.88 for the whole questionnaire and varied between 0.46 and 0.84 for the individual dimensions (20).

Ten PSC dimensions were explored by the French version through 45 items. The questionnaire user's guide defined and described the 10 dimensions related to PSC as follows (19). (D1) Overall perceptions of patient safety: procedures and systems are good at preventing errors and there is a lack of patient safety problems. (D2) Frequency of events reported: mistakes of the following types are reported: (1) mistakes caught and corrected before affecting the patient; (2) mistakes with no potential to harm the patient; and (3) mistakes that could harm the patient but do not. (D3) Supervisor/ manager expectations: supervisors/managers consider staff suggestions for actions promoting and improving patient safety; praising staff for following patient safety procedures; and do not overlook patient safety problems. (D4) Organizational learning - continuous improvement: mistakes have led to positive changes and changes are evaluated for effectiveness. (D5) Teamwork within units: staff support each other, treat each other with respect, and work together as a team. (D6) Communication openness: staff freely speak up if they see something that may negatively affect a patient and feel free to question those with more authority. (D7) Nonpunitive response to errors: staff feel that their mistakes and event reports are not held against them and that mistakes are not kept in their personnel file. (D8) Staffing: there are enough staff to handle the workload, which is appropriate to provide the best care for patients. (D9) Management support for patient safety: hospital management provides a work climate that promotes patient safety and shows that patient safety is a top priority. (D10) Teamwork across units: hospital units cooperate and coordinate with one another to provide the best care for patients.

The questionnaire assesses 10 dimensions deemed related to PSC in a way that if the professionals have a dysfunction in one or more dimensions (score $<50 \%$ ) it reflects a failing PSC. For example, if professionals work in a punitive environment (D7) or have dysfunctional teamwork (D5), it means PSC is failing. To have a welldeveloped PSC, the 10 dimensions must be developed (score $>75 \%)(19)$.

The survey also explored nurses' perception of patient safety quality ( 1 item), and the number of AEs reported during the last 12 months ( 1 item), which referred to the number of events that the nurses responding to the survey reported. The questionnaire also included a section on general information on the participants, which was used to determine the factors associated with PSCeus, namely: professional title (specialty), sex, age, work experience, participation in risk management committees, and district of the primary healthcare centre. 
A Likert scale of 5 points was used to explore participants' PSC perception ranging from 'strongly disagree' to 'strongly agree' or from 'never' to 'always' depending on the nature of the item.

\section{Data collection and ethical considerations}

After obtaining institutional ethics committee approval and administrative authorization from different centres' management, a self-reported paper-based questionnaire was distributed to the participants. The investigator went to the centre and distributed the questionnaire after explaining the aims and outcomes of the study to all the nurses meeting the inclusion criteria and who agreed to respond. They could freely and anonymously fill in the questionnaire and return their responses directly to the investigator. The investigators did not work in the centres and only went to distribute the questionnaires. The data entry and analysis were confided to another researcher.

\section{Data analysis}

Data analysis was performed using SPSS version 20 and Epi info 6.04d for Windows. Descriptive statistical analysis such as frequencies and percentages of positive responses for each item and dimension were used to examine professionals' perceptions about PSC. Items were worded in both positive and negative terms. For items with a positive formulation, answers "strongly agree/ agree" or "most of the time/always" were considered positive. For items with a negative formulation, the answers "strongly disagree/disagree" or "never/rarely" responses were considered positive for PSC.

Items with negative formulation were identified according to the questionnaire's user guide (19) and were coded conversely. According to the user guide, if none of the dimensions' sections was entirely filled, the questionnaire would not be taken into account (19). Also, if fewer than half of the items in the questionnaire were completed, or the same answers were given to all the items, the questionnaire was considered ineligible and excluded (19). A bivariate analysis was carried out to highlight the associations between the sociodemographic and professional data and the different dimensions of PSC. Percentages were compared by Pearson's $\chi^{2}$ test. The materiality threshold was set at 0.05 .

\section{Results}

\section{Participant characteristics}

A total of 138 participants provided survey feedback and the response rate was $87.3 \% ; 92$ (67.7\%) were registered nurses and $46(33.3 \%)$ were specialized nurses (Table 1). Most respondents ( $n=102 ; 73.9 \%)$ were female, and the male:female ratio was 0.35 . One hundred and three $(74.6 \%)$ nurses had work experience of $>10$ years.

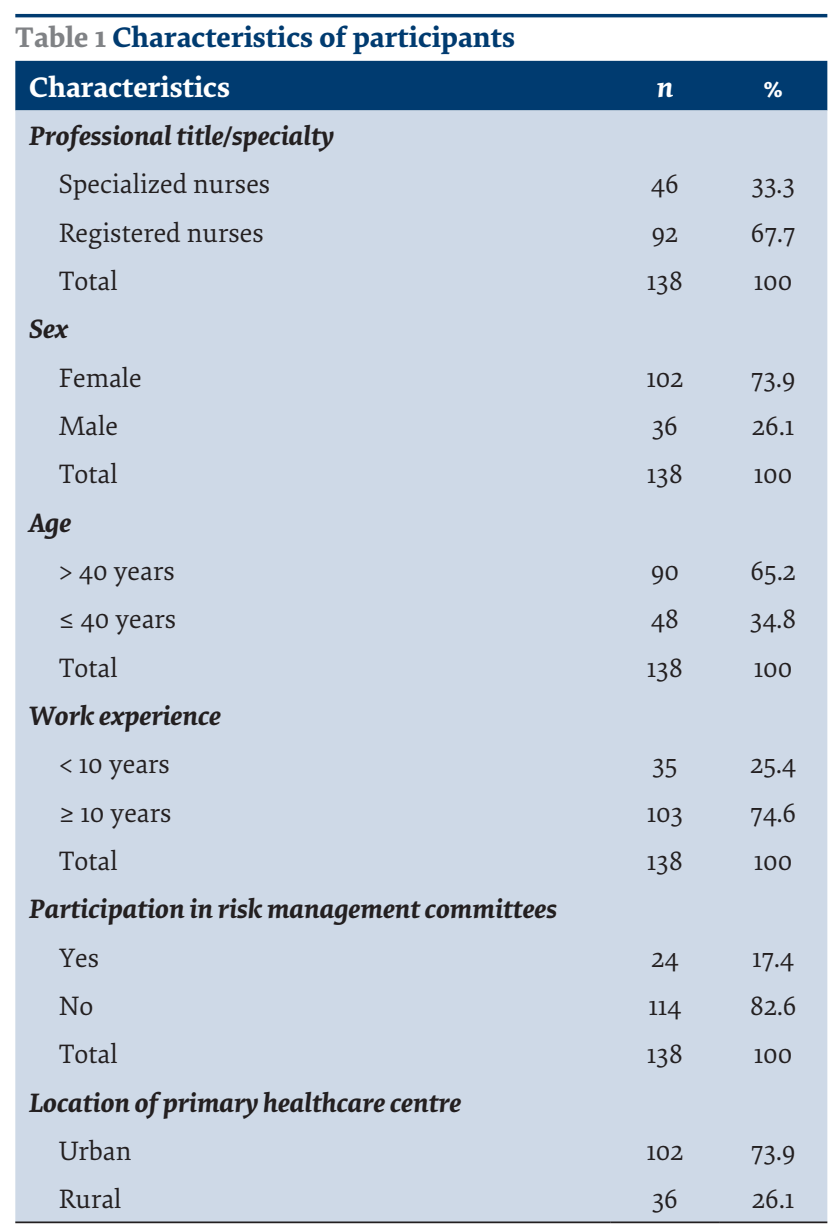

\section{Nurses' perception of patient safety quality and frequency of reported AEs}

Nurses' perception of patient safety quality in the primary healthcare centres was ranked as acceptable in $57.2 \%$ of cases and poor in $17.4 \%$ (Table 2). Ninety-eight (71\%) of the participants declared that they did not report any $\mathrm{AE}$ in the last 12 months.

\section{PSC dimensions}

Overall perception of patient safety had an average positive score of $53.65 \%$ (Table 3). The percentage of positive

\begin{tabular}{lcc}
\hline \multicolumn{3}{c}{ Table 2 Nurses perception of patient safety quality and } \\
number of reported adverse events during the last $\mathbf{1 2}$ & months \\
\hline Nurses perception of patient safety quality & $\mathbf{n}$ & $\%$ \\
\hline Excellent & 9 & 6.5 \\
Very good & 25 & 18.2 \\
Acceptable & 79 & 57.2 \\
Poor & 24 & 17.4 \\
Failing & 1 & 0.7 \\
No. of events reported & $\mathbf{n}$ & $\%$ \\
None & 98 & 71 \\
1 or 2 & 20 & 14.5 \\
3-5 & 8 & 5.8 \\
6-20 & 5 & 3.6 \\
> 20 & 7 & 5.1 \\
\hline
\end{tabular}




\section{Table 3 Scores and items of the 10 dimensions of patient safety culture}

\begin{tabular}{|c|c|c|}
\hline Items of patient safety culture dimensions & $\begin{array}{c}\text { Absolute } \\
\text { frequency ( } n)\end{array}$ & $\begin{array}{l}\text { Average positive } \\
\text { response (\%) }\end{array}$ \\
\hline D1: Overall perceptions of safety & & 53.65 \\
\hline Patient safety is never sacrificed to get more work done & 90 & 65 \\
\hline Our procedures and systems are good at preventing errors from happening & 83 & 59.8 \\
\hline It is just by chance that more serious mistakes do not happen around here & 67 & 48.9 \\
\hline We have patient safety problems in this facility & 56 & 40.9 \\
\hline D2: Frequency of events reported & & 27.7 \\
\hline When a mistake is made, but is caught and corrected before affecting the patient, it is reported & 40 & 29.2 \\
\hline When a mistake is made, but has no potential to harm the patient, it is reported & 33 & 24 \\
\hline When a mistake is made that could harm the patient, but does not, it is reported & 41 & 29.9 \\
\hline D3: Supervisor/manager expectations and actions promoting patient safety & & 53.47 \\
\hline $\begin{array}{l}\text { Manager says a good word when he/she sees a job done according to established } \\
\text { patient safety procedures }\end{array}$ & 85 & 61.3 \\
\hline Manager seriously considers staff suggestions for improving patient safety & 74 & 53.3 \\
\hline Whenever pressure builds up, my manager wants us to work faster, even if it means taking shortcuts & 71 & 51.1 \\
\hline My manager overlooks patient safety problems that happen over and over & 67 & 48.2 \\
\hline D4: Organizational learning and continuous improvement & & 48.66 \\
\hline We are actively doing things to improve patient safety & 94 & 67.9 \\
\hline Mistakes have led to positive changes here & 77 & 55.5 \\
\hline After we make changes to improve patient safety, we evaluate their effectiveness & 106 & 76.6 \\
\hline We are given feedback about changes put into place based on event reports & 14 & 10.2 \\
\hline We are informed about errors that happen in the facility & 47 & 34.3 \\
\hline In this facility, we discuss ways to prevent errors from happening again & 66 & 47.5 \\
\hline D5: Teamwork within units & & 70.6 \\
\hline People support one another in this facility & 93 & 67.1 \\
\hline When a lot of work needs to be done quickly, we work together as a team to get the work done & 109 & 78.8 \\
\hline In facility, people treat each other with respect & 95 & 68.6 \\
\hline When one area in this unit gets really busy, others help out & 94 & 67.9 \\
\hline D6: Communication openness & & 42.13 \\
\hline Staff will freely speak up if they see something that may negatively affect patient care & 70 & 50.4 \\
\hline Staff feel free to question the decisions or actions of those with more authority & 39 & 28.5 \\
\hline Staff are afraid to ask questions when something does not seem right & 66 & 47.5 \\
\hline D7: Nonpunitive response to error & & 36.5 \\
\hline Staff feel like their mistakes are held against them & 49 & 35.8 \\
\hline When an event is reported, it feels like the person is being written up, not the problem & 56 & 40.9 \\
\hline Staff worry that mistakes they make are kept in their personnel file & 45 & 32.8 \\
\hline D8: Staffing & & 34.76 \\
\hline We have enough staff to handle the workload & 67 & 48.9 \\
\hline Staff in this facility work longer hours than is best for patient care & 22 & 16 \\
\hline We work in crisis mode trying to do too much, too quickly & 54 & 39.4 \\
\hline D9: Management support for patient safety & & 51.07 \\
\hline Management provides a work climate that promotes patient safety & 60 & 43.8 \\
\hline The actions of management show that patient safety is a top priority & 79 & 56.9 \\
\hline Management seems interested in patient safety only after an adverse event happens & 58 & 42.3 \\
\hline Units work well together to provide the best care for patients & 85 & 61.3 \\
\hline
\end{tabular}




\begin{tabular}{|c|c|c|}
\hline Items of patient safety culture dimensions & $\begin{array}{c}\text { Absolute } \\
\text { frequency (n) }\end{array}$ & $\begin{array}{l}\text { Average positive } \\
\text { response }(\%)\end{array}$ \\
\hline D10: Teamwork across units & & 45.95 \\
\hline There is good cooperation among units that need to work together & 75 & 54.7 \\
\hline Units do not coordinate well with each other & 55 & 40.1 \\
\hline It is often unpleasant to work with staff from other units & 55 & 40.1 \\
\hline $\begin{array}{l}\text { Things "fall between the cracks" when transferring patients from one } \\
\text { unit to another }\end{array}$ & 53 & 38.7 \\
\hline Important patient care information is often lost during shift changes & 83 & 59.8 \\
\hline Problems often occur in the exchange of information across units & 58 & 42.3 \\
\hline
\end{tabular}

responses was highest for teamwork within units (70.6\%). The lowest scores were for frequency of event reporting (27.7\%), staffing (34.76\%) and nonpunitive response to error $(36.5 \%)$.

\section{Factors associated with PSC}

The dimensions of PSC were not significantly associated with sex, professional title, or work experience. Two factors were associated with PSC dimensions: frequency of AEs reported was significantly higher among participants involved in risk management committees $(P=$ 0.02); and overall perception of safety was significantly higher among nurses working in urban compared with rural districts $(P=0.03)$.

\section{Discussion}

To our knowledge, there have been no studies of PSC among nurses working in primary healthcare in Tunisia. Therefore, the present study was conducted to assess nurses' PSC in Tunisian primary healthcare centres. The dimension of teamwork within units had the highest score $(70.6 \%)$. Three dimensions had low scores, namely, frequency of event reporting $(27.6 \%)$, staffing $(34.76 \%)$ and nonpunitive response to errors (36.5\%). Two factors were associated with PSC: participation in risk management committees, and district of the primary care centre.

Recently, patient safety in primary care has been given increasing attention (22), and many studies have shown a high level of AEs with negative consequences $(1,6,7,23)$. Given the importance of assessing PSC to enhance patient safety in primary care, several studies have sought to determine professionals' PSC in this setting (1,5,9,24-26). Many studies have focused on nurses, in the belief that understanding nurses' perceptions are crucial for policymakers to address PSC in relation to nurses' staffing policies $(12,14,15)$. The dimension of overall perception of safety had a score of $53.65 \%$. This reflects the lack of safety standards in the primary healthcare centres and the need to implement corrective measures to increase awareness of this issue among professionals. Indeed, $59.1 \%$ of nurses confirmed that they had problems with security in their workplace.

We found that the dimension of teamwork within units had the highest score (70.6\%) and this was similar to previous studies $(1,25,27)$. However, when it came to critical care areas such as operating rooms (10) and intensive care units (28), this dimension had a low score ( $41.7 \%$ and $46.99 \%$, respectively). This may be due to the fact that primary healthcare centres are small buildings with fewer staff compared to hospitals and critical care units and are unsophisticated environments that encourage teamwork (29).

Staffing had a positive score of $34.76 \%$, and most nurses reported that they did not have enough staff to handle the workload, and that they worked longer hours than are best for patient care. This situation may have severe negative consequences for patient safety and quality of care. O'Brien-Pallas et al. investigated the relationship between nurse staffing, workload and patient outcomes. They found that nurse staffing (fewer registered nurses), increased workload, and an unstable nursing environment was linked to negative patient outcomes, including falls and medication errors (30). They also reported that when nursing demand/supply levels exceeded $80 \%$, negative outcomes increased for nurses themselves and hospitals, as well as patients.

The dimension that had the lowest score was frequency of events reported (27.7\%). This under-reporting can be explained by the fact that the commission of error is always considered to indicate lack of skill and rarely seen as a learning opportunity. Several barriers exist to reporting AEs, including insufficient time to report, lack of feedback, fear of blame and damage to reputation in a competitive environment, and loss of patient confidence $(11,31)$. This dimension was similar to nonpunitive response to error, which also had a low score (36.5\%). Nurses reported that they felt that their mistakes were held against them and their involvement in the $\mathrm{AE}$ was being highlighted rather than the $\mathrm{AE}$ itself. This problem of under-reporting AEs must be taken into consideration and treated with vigilance; nurses should be encouraged to report AEs and even rewarded for so doing. It is essential to establish a culture in which individuals are supported to identify and report AEs without threat of punitive action or blame. Reporting of AEs is an integral part of a continuous cycle of improving patient safety and quality of care that includes error identification, reporting, analysis and corrective actions (32). 
In our study, participants who were engaged in risk management committees had a significantly higher score for the dimension frequency of events reported $37.2 \%$ vs $17.7 \% ; P=0.02$ ). This finding agrees with results from the PSC survey that was conducted in operating rooms in Tunisia (10). Risk management describes a dynamic process that includes all measures for systematic identification, analysis, assessment, surveillance and control of risks. An effective risk management should not start only after the evaluation of an incident but when failure can still be avoided and damage can be prevented.

Overall perception of safety was significantly more developed among nurses working in urban than in rural areas $(60.1 \%$ vs $40.2 \% ; P=0.03)$. This difference can be explained by the fact that, in Tunisia, urban healthcare institutions are better equipped with more sophisticated equipment and better human and material resources.

We recommend systematic improvement of staff qualifications by providing training opportunities and educational interventions to promote better understanding of the principles of teamwork, help staff acknowledge each other's roles and perspectives, and develop effective communication strategies. At the level of practice, policy-making, administration, research and curriculum, we recommend improved training of nurses regarding patient safety. To this end, the World Health Organization has published 2 guides: the first is for students, to be integrated into health universities (Patient Safety Curriculum Guide for Medical Schools) (33); and the second is designed for health professionals as part of continuing education (Patient Safety Curriculum Guide Multi-professional Edition) (34). Improvement of quality of care and patient safety by implementing a quality management system is essential, with managerial training concerning communication and nursing leadership. Nurses need to feel protected and encouraged to report errors and AEs, and introduction of an anonymous reporting system that protects the reporter is therefore recommended.

Our study had some limitations. First, assessment of PSC using a self-administered questionnaire could have been associated with declaration bias. A self-administered questionnaire may influence the responses of those who, for fear of reprisal or prosecution, give desirable answers that do not reflect reality. Second, HSOPSC did not allow us to calculate an overall score for PSC for all the targeted centres, which would have allowed rapid comparison of quality of care and safety culture between healthcare organizations. By following the questionnaire guidelines, we were only able to calculate a score for each dimension without calculating a mean score for all the dimensions combined. Third, there was possible recall bias, specifically when remembering the number of AEs reported, resulting in possible under- or overestimation of reported results. Finally, even though we included all the training centres of the targeted region, the sampling technique did not allow us to assume that these included settings were representative of the entire primary healthcare system in Tunisia.

\section{Conclusions}

Our findings demonstrated that none of the PSC dimensions were developed in our primary healthcare centres. We highlighted different areas of concern, such as frequency of events reported, nonpunitive response to error, and staffing. More attention should be paid to PSC in primary healthcare because changing values and attitudes needs time and motivation through training and improving risk management skills among nurses. Also, the results highlight the necessity of implementation of quality management systems in Tunisian primary healthcare centres. Strategies to nurture PSC should focus upon building leadership capacity that supports open communication, blame-free environment, teamwork and continuous organizational learning.

\section{Acknowledgement}

We thank the professionals in all the centres where the study was conducted for their cooperation and the supportive working conditions that they offered.

Funding: None.

Competing interests: None declared.

\section{Évaluation de la culture de la sécurité des patients chez le personnel infirmier dans 30 centres de soins de santé primaires en Tunisie}

\section{Résumé}

Contexte : Garantir la sécurité des patients et la qualité des soins de santé demeure une priorité et un défi dans le monde entier face auxquels le personnel infirmier joue un rôle essentiel. Le développement de la culture de la sécurité des patients constitue un élément clé pour améliorer la sécurité de ces derniers ainsi que la qualité des soins de santé.

Objectifs : Évaluer la culture de la sécurité des patients chez le personnel infirmier dans les centres de soins de santé primaires tunisiens et déterminer les facteurs qui y sont associés. 
Méthodes : Il s'agissait d'une étude descriptive transversale multicentrique menée dans 30 centres de soins de santé primaire tunisiens à l'aide de la version française validée du questionnaire de l'enquête hospitalière sur la culture de la sécurité des patients. L'ensemble du personnel infirmier travaillant dans ces centres a été invité à participer à l'étude $(\mathrm{n}=158)$.

Résultats : Le taux de réponse concernant la participation à l'étude a été de 87,3\%. La dimension «travail d'équipe au sein des unités » a obtenu le score le plus élevé (70,6\%). Trois dimensions de la sécurité présentaient des scores faibles : «fréquence de notification des événements » $(27,6 \%)$, « dotation en personnel » $(34,76 \%)$ et « réponse non punitive à l'erreur » (36,5\%). Deux facteurs étaient associés à la culture de la sécurité des patients : la participation aux comités de gestion des risques et le district du centre de soins primaires.

Conclusions : Le niveau de culture de la sécurité des patients chez le personnel infirmier doit être amélioré dans les centres de soins de santé primaires en Tunisie. Les stratégies visant à développer la culture de la sécurité des patients doivent porter sur le renforcement des capacités d'encadrement qui favorisent une communication ouverte, un environnement professionnel bienveillant, le travail d'équipe et un apprentissage organisationnel continu.

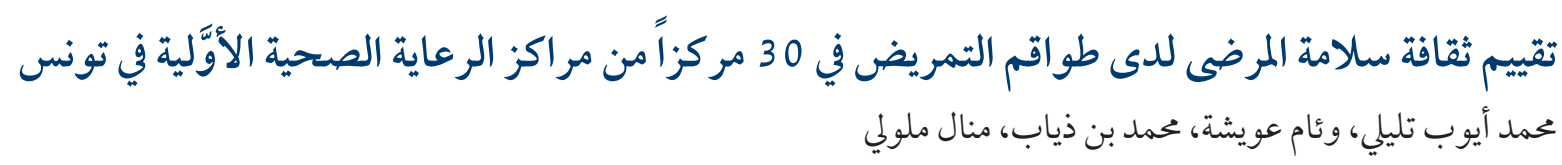

الخلاصة

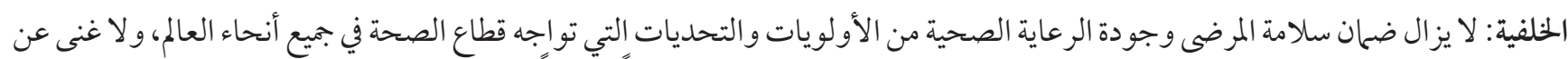

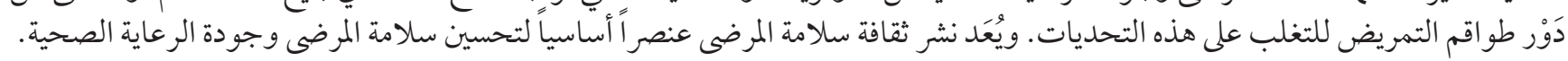
الأهداف: هدفت هذه الدراسة إلى تقييم ثقافة سلامة المرضى لدى طو اقم التمريض في مر اكز الرعاية الصحية الأوَّلية في تونس، وتحديد العو امل المرتبطة بها.

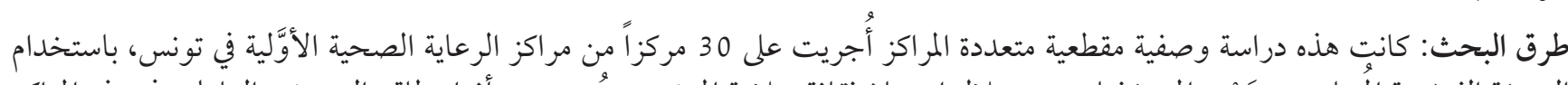

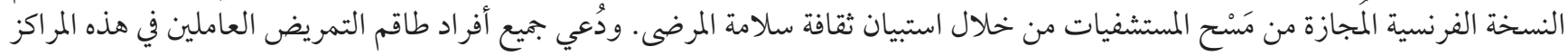

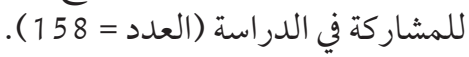

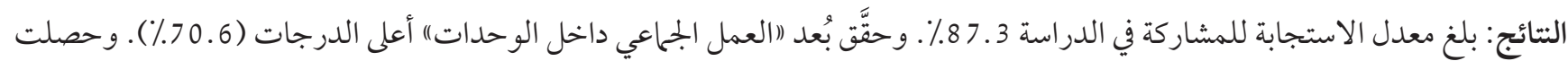

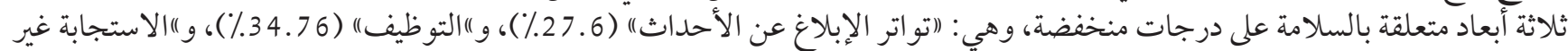

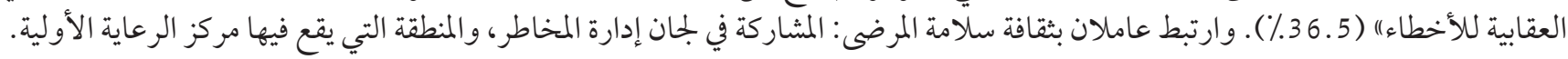

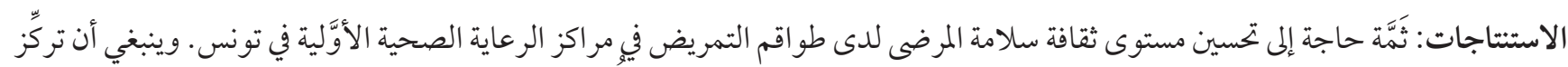

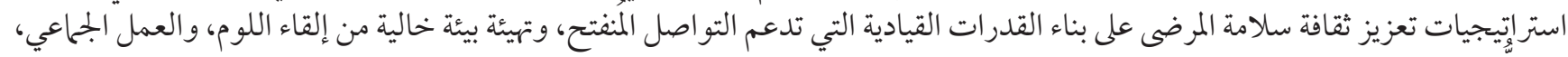
و التعلمّم التنظيمي المستمر.

\section{References}

1. Bodur S, Filiz E. A survey on patient safety culture in primary healthcare services in Turkey. Int J Qual Health Care. 2009 Oct;21(5):348-55. https://doi.org/10.1093/intqhc/mzpo35.

2. Occelli P, Quenon J-L, Hubert B, Hoarau H, Pouchadon M-L, Amalbert R, et al. La culture de sécurité en santé: un concept en pleine émergence. Risques Qualite. 2007;5:207-12 (in French).

3. Bouafia N, Bougmiza I, Bahri F, Letaief M, Astagneau P, Njah M. Ampleur et impact des évènements indésirables graves liés aux soins: Étude d'incidence dans un hôpital du Centre-Est tunisien. Pan Afr Med J. 2014;16 (in French). https://doi.org/10.11604/ pamj.2013.16.68.1161.

4. Zegers M, De Bruijne MC, Spreeuwenberg P, Wagner C, Van Der Wal G, Groenewegen PP. Variation in the rates of adverse events between hospitals and hospital departments. Int J Qual Health Care. 2011 Apr;23(2):126-33. https://doi.org/10.1093/intqhc/ mzq086.

5. Webair HH, Al-assani SS, Al-haddad RH, Al-Shaeeb WH, Bin Selm MA, Alyamani AS. Assessment of patient safety culture in primary care setting, Al-Mukala, Yemen. BMC Fam Pract. 2015;16:Article number 136. https://doi.org/10.1186/s12875-015-0355-1.

6. Dovey SM, Meyers DS, Phillips RL, Green LA, Fryer GE, Galliher JM, et al. A preliminary taxonomy of medical errors in family practice. Qual Saf Health Care. 2002 Sep;11(3):233-8. http://dx.doi.org/10.1136/qhc.11.3.233 PMID:12486987

7. Rosser W, Dovey S, Bordman R, White D, Crighton E, Drummond N. Medical errors in primary care: results of an international study of family practice. Can Fam Physician. 2005 Mar;51:386-7. PMID:16926931 
8. Aranaz-Andrés JM, Aibar C, Limón R, Mira JJ, Vitaller J, Agra Y, et al. A study of the prevalence of adverse events in primary healthcare in Spain. Eur J Public Health. 2012 Dec;22(6):921-5. https://doi.org/10.1093/eurpub/ckr168

9. Chen I-C, Li H-H. Measuring patient safety culture in Taiwan using the Hospital Survey on Patient Safety Culture (HSOPSC). BMC Health Serv Res. 2010;10:Article number 152. https://doi.org/10.1186/1472-6963-10-152

10. Mallouli M, Tlili MA, Aouicha W, Ben Rejeb M, Zedini C, Salwa A, et al. Assessing patient safety culture in Tunisian operating rooms: a multicenter study. Int J Qual Health Care. 2017 Apr;29(2):176-82. https://doi.org/10.1093/intqhc/mzw157

11. El-Jardali F, Jaafar M, Dimassi H, Jamal D, Hamdan R. The current state of patient safety culture in Lebanese hospitals: a study at baseline. Int J Qual Health Care. 2010 Oct;22(5):386-95. https://doi.org/10.1093/intqhc/mzq047

12. Ammouri AA, Tailakh AK, Muliira JK, Geethakrishnan R, Al Kindi SN. Patient safety culture among nurses. Int Nurs Rev. 2015 Mar;62(1):102-10. http://dx.doi.org/10.1111/inr.12159 PMID: 25495946

13. Nieva VF, Sorra J. Safety culture assessment: a tool for improving patient safety in healthcare organizations. Qual Saf Health Care. 2003;12 Suppl 2:ii17-23. http://dx.doi.org/10.1136/qhc.12.suppl_2.ii17

14. Khater WA, Akhu-Zaheya LM, AL-Mahasneh SI, Khater R. Nurses' perceptions of patient safety culture in Jordanian hospitals. Int Nurs Rev. 2015 Mar;62(1):82-91. http://dx.doi.org/10.1111/inr.12155 PMID:25439981

15. Abdou HA, Saber KM. A baseline assessment of patient safety culture among nurses at student university hospital. World J Med Sci. 2011 Jan;6(1):17-26.

16. Richardson A, Storr J. Patient safety: a literature [corrected] review on the impact of nursing empowerment, leadership and collaboration. Int Nurs Rev. 2010 Mar;57(1):12-21. https://doi.org/10.1111/j.1466-7657.2009.00757.x

17. Cheikh AB, Bouafia N, Mahjoub M, Ezzi O, Nouira A, Njah M. Patient's safety culture among Tunisian healthcare workers: results of a cross sectional study in university hospital. Pan Afr Med J 20163 Aug;24:Article 299. https://doi.org/10.11604/ pamj.2016.24.299.8466

18. Ben Rejeb M, Chebil D, Merzougui L, Kacem B, Khefacha-Aissa S, Dhidah L, et al. Patient safety culture in a Tunisian teaching tertiary care hospital. Arch Nurs Pract Care. 2017;3(1):077-83. http://dx.doi.org/10.17352/2581-4265.000030

19. Comité de Coordination de l'évaluation Clinique et de la Qualité en Aquitaine. Mesure de la culture de sécurité des soins dans les établissements de santé: guide d'utilisation; 2015.

20. Occelli P, Quenon J-L, Kret M, Domecq S, Delaperche F, Claverie O, et al. Validation of the French version of the Hospital Survey on Patient Safety Culture questionnaire. Int J Qual Health Care 2013 Sep;25(4):459-68. https://doi.org/10.1093/intqhc/mzto47

21. Giai J, Boussat B, Occelli P, Gandon G, Seigneurin A, Michel P, et al. Hospital survey on patient safety culture (HSOPS): variability of scoring strategies. Int J Qual Health Care 2017 Oct;29(5):685-92. https://doi.org/10.1093/intqhc/mzxo86

22. Verbakel NJ, Zwart DL, Langelaan M, Verheij TJ, Wagner C. Measuring safety culture in Dutch primary care: psychometric characteristics of the SCOPE-PC questionnaire. BMC Health Serv Res 2013;13:Article number 354. https://doi.org/10.1186/14726963-13-354

23. Sandars J, Esmail A. The frequency and nature of medical error in primary care: understanding the diversity across studies. Fam Pract 2003 Jun;20(3):231-6. https://doi.org/10.1093/fampra/cmg301

24. Smits M, Christiaans-Dingelhoff I, Wagner C, Wal G van der, Groenewegen PP. The psychometric properties of the "Hospital Survey on Patient Safety Culture" in Dutch hospitals. BMC Health Serv Res 2008;8: Article number 230. https://doi. org/10.1186/1472-6963-8-230

25. Mohamed AM, Ali MS, Gewaifel GI. Assessment of Patient Safety Culture in Primary Healthcare Services in Alexandria, Egypt. Glob J Epidemiol Public Health 2015;2:5-14. http://dx.doi.org/10.12974/2313-0946.2015.02.01.1

26. Tabrizchi N, Sedaghat M. The first study of patient safety culture in Iranian primary health centers. Acta Med Iran 2012;50(7):505-10. PMID:22930384

27. Ghobashi MM, El-ragehy HAG, Ibrahim HM, Al-Doseri FA. Assessment of patient safety culture in primary health care settings in Kuwait. Epidemiol Biostat Public Health 2014;11(3). https://doi.org/10.2427/9101

28. Minuzzi AP, Salum NC, Locks MOH. Avaliação da cultura de segurança do paciente em terapia intensiva na perspectiva da equipe de saúde. Texto Contexto Enferm 2016;25(2) (in Portuguese). https://doi.org/10.1590/0104-07072016001610015

29. Wilson T, Pringle M, Sheikh A. Promoting patient safety in primary care. BMJ 2001 Sep 15;323(7313):583-4. http://dx.doi. org/10.1136/bmj.323.7313.583 PMID:11557689

30. Duffield C, Diers D, O'Brien-Pallas L, Aisbett C, Roche M, King M, et al. Nursing staffing, nursing workload, the work environment and patient outcomes. Appl Nurs Res. 2011 Nov;24(4):244-55. https://doi.org/10.1016/j.apnr.2009.12.004

31. Rea D, Griffiths S. Patient safety in primary care: incident reporting and significant event reviews in British general practice. Health Soc Care Community 2016 Jul;24(4):411-9. https://doi.org/10.1111/hsc.12221

32. Cooke DL, Dunscombe PB, Lee RC. Using a survey of incident reporting and learning practices to improve organisational learning at a cancer care centre. BMJ Qual Saf. 2007;16:342-8. https://doi.org/10.1136/qshc.2006.018754

33. Patient safety curriculum guide for medical schools 2009. Geneva: World Health Organization; 2009 (https://apps.who.int/iris/ bitstream/handle/10665/44091/9789241598316_eng.pdf?sequence=1\&isAllowed=y, accessed 25 April 2020).

34. Patient safety curriculum guide: multi-professional edition. Geneva: World Health Organization; 2011 (https://apps.who.int/iris/ handle/10665/44641, accessed 25 April 2020). 